\title{
Emprego da farinha e do extrato de frutanos de yacon na elaboração de apresuntados
}

\author{
Use of yacon flour and fructan extract in the formulation of luncheon meats
}

Autores | Authors

\section{Ellem Waleska Nascimento da} Fonseca CONTADO

Universidade Federal de Lavras (UFLA) Departamento de Ciência dos Alimentos Lavras/MG - Brasil e-mail: ellem.waleska@ig.com.br

Denise Alvarenga ROCHA

Universidade Federal de Lavras (UFLA) Departamento de Química Lavras/MG - Brasil e-mail:deniserocha3@hotmail.com

*Estela de Rezende QUEIROZ

Universidade Federal de Lavras (UFLA) Departamento de Química Caixa Postal 3037 CEP: 37200-000 Lavras/MG - Brasil e-mail: estelaqueiroz@yahoo.com.br

Celeste Maria Patto de ABREU

Universidade Federal de Lavras (UFLA) Departamento de Química Lavras/MG - Brasil e-mail: celeste@dqi.ufla.br

Eduardo Mendes RAMOS

Universidade Federal de Lavras (UFLA) Departamento de Ciência dos Alimentos Lavras/MG - Brasil e-mail:eramos@dca.ufla.br

*Autor Correspondente / Corresponding Author

Recebido: Jul. 23, 2014

Aprovado: Mar. 09, 2015

\section{Resumo}

O objetivo deste estudo foi desenvolver duas formulações de apresuntado contendo farinha de yacon e extrato de frutanos de yacon visando obter produtos de melhor qualidade nutricional e ricos em fibras alimentares. Os apresuntados foram elaborados substituindo-se a fécula de mandioca $(1,73 \%)$ pela farinha de yacon e a água da formulação $(37,85 \%)$ pelo extrato aquoso de frutanos. Os efeitos dessas substituições nas qualidades tecnológicas e sensoriais dos apresuntados foram avaliados comparando-os com um controle. Os resultados obtidos demonstraram existirem diferenças significativas entre as formulações e evidenciaram que a adição da farinha de yacon ao apresuntado originou uma formulação com menor teor de sódio, índice de amarelo, tonalidade, dureza, flexibilidade, adesividade e menores notas nos quesitos sabor e impressão global. Entretanto revelaram que o apresuntado elaborado com extrato de frutanos apresentou uma aceitabilidade semelhante ao controle, porém com menor dureza e maiores teores de potássio e fibras, originando um produto cárneo benéfico à saúde.

Palavras-chave: Composição química; Cor; Textura objetiva; Análise sensorial.

\section{Summary}

The objective of this study was to develop two luncheon meat formulations containing yacon flour and yacon fructan extract, in order to obtain products with improved nutritional quality and rich in dietary fiber. The luncheon meats were prepared replacing the cassava starch $(1.73 \%)$ with yacon flour, and the water used in the formulation (37.85\%) with the aqueous fructan extract. The effects of these substitutions on the technological and sensory qualities of the luncheon meats were evaluated, comparing them with a control. The results obtained showed there were significant differences between the formulations. The addition of yacon flour to the luncheon meat resulted in a formulation with a lower sodium content, yellow index, hue, hardness, flexibility and adhesion and lower scores for the items of taste and overall impression. However, they showed that the luncheon meat prepared with the fructan extract presented an acceptability similar to that of the control, but with reduced hardness and higher levels of potassium and fiber, resulting in a meat product beneficial to the health.

Key words: Chemical composition; Color; Objective texture; Sensory analysis. 


\section{Introdução}

A variedade de produtos cárneos que não demandam muito tempo para o preparo disponibilizada nas gôndolas de supermercados tornou-se um atrativo para os consumidores, contribuindo para que salsicha, salame, mortadela, linguiça, empanados, almôndegas e hambúrgueres sejam opções crescentes para o lanche de muitas famílias no mundo todo (OLIVEIRA et al., 2013).

No Brasil, houve um aumento do consumo de produtos cárneos processados nos últimos anos, inclusive de presuntos crus (COSTA et al., 2007) e apresuntados, produtos que apresentam uma enorme difusão no mercado. Percebendo essa tendência, a indústria de alimentos tem buscado o desenvolvimento de produtos com custo acessível e que atendam às expectativas do consumidor, principalmente no quesito saúde.

A modificação do hábito alimentar é um consenso como recomendação para prevenção e tratamento de doenças crônicas não transmissíveis como: doenças cardiovasculares, intestinais, cânceres, diabetes e dislipidemias. A indústria de alimentos precisa se adequar a esses desafios por meio do desenvolvimento de produtos mais saudáveis nutricionalmente, com propriedades funcionais e que apresentem, também, características sensoriais iguais ou superiores aos alimentos tradicionais (SAAD, 2006; VIDAL et al., 2012).

O yacon (Smallanthus sonchifolia Poep. Endl.) é uma espécie da família Asteraceae, originária da região dos Andes, e seus rizóforos e tubérculos contêm grandes quantidades de fruto-oligossacarídeos do tipo inulina, fibras e minerais, o que o torna benéfico para a alimentação humana (MARTINS et al., 2011).

O desenvolvimento de produtos ricos em fibras alimentares utilizando a raiz do yacon pode ser uma excelente alternativa, uma vez que, diferentemente da maioria dos tubérculos que acumulam carboidratos na forma de amido, o yacon e várias plantas da família Asteracea armazenam carboidratos na forma de frutanos. Esses são carboidratos compostos principalmente por monômeros de frutose com um grau de polimerização que varia de 2 a 70 monossacarídeos (PASCOAL et al., 2013), podendo apresentar uma molécula terminal de sacarose (ROBERFROID e DELZENNE, 1998). O tubérculo yacon contém de $60 \%$ a $70 \%$ de frutanos do tipo inulina, com grau de polimerização máximo de 12 unidades de frutose (DOUGLAS et al., 2007; OLIVEIRA et al., 2009).

Os fruto-oligossacarídeos são considerados fibras alimentares solúveis. Apresentam diversas aplicações na indústria de alimentos, podendo ser utilizados como ingredientes nutracêuticos, no desenvolvimento de produtos com "baixo valor calórico" e, por seu efeito prebiótico, como alimento com propriedades funcionais (FORTES, 2006).
A incorporação de fibras a alimentos frequentemente consumidos, como apresuntados, além de ser usada com propósitos econômicos e tecnológicos, pode contribuir para a ingestão diária de fibra pela população (GUILLON e CHAMP, 2000; COLMENERO et al., 2005). A fibra é aplicada em produtos cárneos pois, devido à sua capacidade de retenção de água e gordura (CHOI et al., 2009; CYRINO e BARRETO, 2006), auxilia na redução da quebra de cozimento e estabiliza emulsões.

Assim, a adição de fibra alimentar a produtos cárneos pode aumentar o rendimento, reduzir o custo da formulação, melhorar a textura, influenciar o comportamento reológico e sensorial, em especial aparência e sabor (BARRETO, 2007; MENDOZA et al., 2001).

Dessa forma, objetivou-se avaliar os efeitos tecnológicos da elaboração de apresuntados com baixo teor de gordura adicionados de farinha e extrato de yacon, bem como a aceitação sensorial dos produtos elaborados.

\section{Material e métodos}

O experimento foi desenvolvido no Departamento de Química e no Departamento de Ciência dos Alimentos da Universidade Federal de Lavras (UFLA), em Lavras, MG. Os tubérculos de yacon foram adquiridos numa fazenda comercial, localizada no município de São Joaquim das Bicas, MG, latitude: $20^{\circ} 02^{\prime} 57^{\prime \prime}$ S, longitude: 441'ㄷ' W. Quarenta quilos desse tubérculo foram lavados em água corrente, com escovação manual, secos, pesados e usados para compor os tratamentos.

O extrato de frutanos do yacon foi elaborado conforme metodologia descrita por Cabello (2005). Para tanto, os yacons foram triturados em liquidificador, filtrados e lavados com água deionizada a $95^{\circ} \mathrm{C}$. O $\mathrm{pH}$ do filtrado foi ajustado para 9,5-9,8 com $\mathrm{NaOH}$ e o filtrado foi mantido em banho-maria a $95^{\circ} \mathrm{C}$ por 2 horas. A solução foi filtrada a vácuo, envazada em recipiente de vidro e armazenada à temperatura de $-18{ }^{\circ} \mathrm{C}$, para utilização posterior.

Para o preparo da farinha, o yacon foi descascado e imerso em solução de 0,02\% de bissulfito de sódio, visando evitar o seu escurecimento enzimático. Em seguida, ele foi picado em tiras ( $3 \mathrm{~mm}$ ) e seco em estufa de circulação de ar mecânica Fanem, modelo 320 SE, a $65{ }^{\circ} \mathrm{C}$, até peso constante. O material seco foi triturado em gral com pistilo, para obtenção de uma farinha fina, a qual foi armazenada em frasco de vidro âmbar, a temperatura ambiente.

A elaboração dos apresuntados seguiu a formulação e os procedimentos relatados por Botega et al. (2009), utilizando os ingredientes que constam na Tabela 1. Além do apresuntado controle, foram elaboradas duas formulações: na primeira se substituiu a fécula de 
Tabela 1. Formulação básica para a elaboração de apresuntados.

\begin{tabular}{|c|c|c|c|c|}
\hline Ingredientes/Aditivos & $\%$ & $\begin{array}{l}\text { Formulação } \\
\text { controle (g) }\end{array}$ & $\begin{array}{c}\text { Formulação com } \\
\text { farinha de yacon }(\mathrm{g})^{*}\end{array}$ & $\begin{array}{l}\text { Formulação com } \\
\text { extrato de frutanos }(g)^{* *}\end{array}$ \\
\hline Carne da paleta suína & 54,07 & 540,70 & 540,70 & 540,70 \\
\hline Proteína de soja isolada (PTS) SUPRO 500E & 1,73 & 17,30 & 17,30 & 17,30 \\
\hline Água & 37,85 & 378,50 & 378,50 & -- \\
\hline Sal & 0,97 & 9,73 & 9,73 & 9,73 \\
\hline CEAM-GEL M 920 & 0,06 & 0,65 & 0,65 & 0,65 \\
\hline REND MAX 208 & 1,73 & 17,30 & 17,30 & 17,30 \\
\hline E MAX 206 & 1,08 & 10,81 & 10,81 & 10,81 \\
\hline MAX SABOR 207 & 0,27 & 2,70 & 2,70 & 2,70 \\
\hline Corante carmim & 0,01 & 0,14 & 0,14 & 0,14 \\
\hline Condimento Califórnia & 0,49 & 4,86 & 4,86 & 4,86 \\
\hline Fécula de mandioca & 1,73 & 17,30 & -- & 17,30 \\
\hline Farinha de yacon & -- & -- & 17,30 & -- \\
\hline Extrato de frutanos & -- & -- & -- & 378,50 \\
\hline
\end{tabular}

${ }^{*}$ Apresuntado elaborado substituindo-se a fécula de mandioca pela farinha de yacon; ${ }^{*}$ Apresuntado elaborado substituindo-se a água pelo extrato de frutanos de yacon.

mandioca pela farinha de yacon e na segunda a água da formulação foi substituída pelo extrato de frutanos do yacon.

A carne (paleta suína) foi adquirida em comércio varejista do município de Lavras, MG, e os demais ingredientes cedidos pela New Max Industrial. As paletas suínas refrigeradas $\left(4^{\circ} \mathrm{C}\right)$ foram limpas e moídas em disco de $20 \mathrm{~mm}$. A salmoura foi adicionada à massa cárnea, a qual foi submetida à mistura por 10 minutos. Em seguida, adicionou-se a proteína de soja texturizada e a massa obtida foi, então, mantida por 12 a 15 horas, em câmara fria $\left(4^{\circ} \mathrm{C}\right)$. Após a cura, adicionou-se a fécula de mandioca e a mistura foi embalada a vácuo, em embalagem flexível de à base de poliamida e polietileno de baixa densidade e enformada.

Os apresuntados foram cozidos na seguinte programação: $60^{\circ} \mathrm{C} / 60$ minutos, $70^{\circ} \mathrm{C} / 60$ minutos e $80^{\circ} \mathrm{C}$ até a temperatura interna da massa atingir $73^{\circ} \mathrm{C}$. Após o cozimento aplicou-se um choque térmico (resfriamento) e os apresuntados foram desenformados e acondicionados sob refrigeração $\left(4^{\circ} \mathrm{C}\right)$, para posterior análise.

Os apresuntados foram analisados 24 horas após a elaboração quanto à composição físico-química e química, teores de sódio e potássio, cor objetiva, textura objetiva e avaliação sensorial.

Para a determinação da composição proximal, os teores de lipídios (extrato etéreo), proteína bruta $(\mathrm{N} \times 6,25)$, cinzas e fibra alimentar foram quantificados utilizando-se o método descrito pela Association of Official Agricultural Chemistry (LATIMER JUNIOR, 2012). O carboidrato foi determinado por diferença entre 100 e a soma das demais frações da composição (umidade, cinzas, proteínas e lipídeos). A umidade foi calculada por gravimetria e o valor energético total (VET), pela soma das calorias fornecidas por carboidratos, lipídios e proteínas, multiplicando-se seu valor em gramas pelos fatores de Atwater: 4 kcal, 9 kcal e 4 kcal, respectivamente.

Os teores de potássio e sódio foram determinados após digestão nitroperclórica, na proporção de 2:1 (ácido nítrico e ácido perclórico). Iniciou-se a digestão na temperatura de $50{ }^{\circ} \mathrm{C}$, aumentando-se gradualmente a temperatura até $210^{\circ} \mathrm{C}$, conforme metodologia descrita por Malavolta et al. (1997), utilizando-se um fotômetro de chama Micronal, modelo B262, a $1.000{ }^{\circ} \mathrm{C}$, pressão de 0,5 a 1,0 bar e gás butano e ar comprimido. Esses minerais foram analisados em sete repetições para cada tipo de apresuntado.

A avaliação objetiva da cor final dos produtos foi realizada em colorímetro Chroma Meters CR-300 (Konica Minolta Sensing Inc.) segundo metodologia descrita por Ramos e Gomide (2007). A luminosidade $\left(L^{*}\right)$, índice de vermelho $\left(a^{*}\right)$ e índice de amarelo $\left(b^{*}\right)$ foram obtidos, para cada repetição, considerando-se o valor médio de cinco leituras realizadas em diferentes pontos de três fatias. $O$ índice de saturação $\left(C^{*}\right)$ e o ângulo de tonalidade $\left(h^{*}\right)$ foram calculados pelas Equações 1 e 2, respectivamente.

$$
\begin{aligned}
& \mathrm{C}^{*}=\left(\mathrm{a}^{* 2}+\mathrm{b}^{* 2}\right)^{1 / 2} \\
& \mathrm{~h}^{*}=\tan ^{-1}\left(\mathrm{~b}^{*} / \mathrm{a}^{*}\right)
\end{aligned}
$$

A textura objetiva dos produtos elaborados foi avaliada por meio da análise de perfil de textura (TPA), utilizando-se um texturômetro TA.XT2i Texture Analysis (Stable Micro System Inc.) conectado a um computador equipado com o programa Texture Expert ${ }^{\circledR}$. Os testes foram conduzidos segundo metodologia descrita por Ramos e Gomide (2007), com as adaptações para apresuntado sugeridas por Botega et al. (2009). Sete amostras cúbicas com $1,0 \mathrm{~cm}$ de diâmetro e 1,0 cm de 
comprimento de cada tratamento foram comprimidas paralelamente ao seu comprimento, por duas vezes, até $50 \%$ de seu tamanho, com um prato de compressão de $7,5 \mathrm{~cm}$ de diâmetro. Não houve tempo de repouso da amostra entre os dois ciclos de compressão. A curva de deformação com o tempo foi obtida a uma velocidade de compressão de $180 \mathrm{~mm} /$ minuto $(0,83 \mathrm{~mm} / \mathrm{s})$, a partir da qual foram gerados seis parâmetros de textura segundo fraturabilidade, dureza, coesividade, adesividade, elasticidade e mastigabilidade.

A aceitação dos apresuntados foi avaliada utilizando-se teste afetivo. As amostras foram servidas acompanhadas de água, para lavagem do palato, em recipientes codificados com número aleatório de três dígitos, e sua apresentação foi balanceada entre os provadores para minimizar o efeito da ordem de apresentação nos julgamentos. Cento e vinte e nove consumidores potenciais do produto ( 72 homens e 54 mulheres), com idade entre 19 e 58 anos, estudantes, professores e funcionários da Universidade Federal de Lavras, avaliaram de forma monádica cada amostra de apresuntado. Foram avaliados os atributos textura, sabor e impressão global. Para isso foi utilizada escala hedônica estruturada de 9 pontos correspondentes a: péssimo, muito ruim, moderadamente ruim, ligeiramente ruim, indiferente, ligeiramente boa, moderadamente boa, muito boa e ótima.

O experimento foi conduzido em delineamento inteiramente casualizado (DIC), sendo três tratamentos, analisados em sete repetições. Os resultados das caracterizações físico-químicas e químicas e dos atributos sensoriais foram submetidos à análise de variância (Anova) e ao teste de Tukey a 5\% de probabilidade, por meio do programa Sisvar (FERREIRA, 2000).

\section{Resultados e discussão}

A composição proximal e o valor energético total dos apresuntados estão representados na Tabela 2. Os teores de umidade (em g $100 \mathrm{~g}^{-1}$ ) dos apresuntados controle e elaborados com farinha de yacon e com extrato de frutanos foram de 78,22, 76,02 e 75,56, respectivamente, observando-se maior conteúdo de água no controle. Essa diferença entre as formulações sugere que a fécula de mandioca tem maior capacidade de retenção de água do que a farinha de yacon. Esse fenômeno provavelmente se deve ao fato de o amido da mandioca começar a gelatinizar na mesma temperatura em que a carne começa a cozer. Dessa forma, é necessário menor quantidade de amido de mandioca para reter água e obter produtos suculentos que de amidos de outros tipos de tubérculos (PSZCZOLA, 1999).

Verificou-se que os teores de lipídios, proteínas, cinzas e o valor energético total não diferiram significativamente $(p>0,05)$ entre os tratamentos.
O apresuntado elaborado com extrato de frutanos apresentou o maior teor de fibras $\left(2,78 \mathrm{~g} 100 \mathrm{~g} \mathrm{~g}^{-1}\right)$, promovendo um aumento de $93,05 \%$ no teor de fibra do apresuntado, em relação ao controle (Tabela 2), fato que era esperado, uma vez que os frutanos são considerados fibras alimentares.

A legislação brasileira preconiza que produtos cárneos devem apresentar teor de proteína acima de 13\% e relação umidade/proteína 5,35\% (BRASIL, 2000). Assim, todas as formulações de apresuntados apresentam teores de proteínas dentro dos padrões, no entanto as relações umidade/proteína estão ligeiramente superiores ao estabelecido.

Os valores de potássio $\left(\mathrm{mg} \mathrm{g}^{-1}\right)$ presente nos apresuntados controle, elaborados com extrato de frutanos e com farinha de yacon foram, respectivamente: $0,794,0,838$ e 0,838, enquanto que os teores de sódio foram, respectivamente: $42,34,43,47$ e 41,46 para os mesmos apresuntados supracitados.

Segundo Moura (2004), o potássio é o mineral encontrado em maior quantidade no yacon (120,8 mg $100 \mathrm{~g}^{-1}$ matéria fresca). Dessa forma, nota-se que os teores de potássio encontrados nos apresuntados elaborados com extrato de frutanos e com farinha de yacon foram maiores que os observados no controle, o que pode ser justificado pelo fato de o yacon ser rico nesse mineral. Adicionalmente, os teores de sódio diferiram nas três formulações de apresuntado. Observa-se que a formulação com extrato de frutanos

Tabela 2. Composição proximal e concentração de Na e K nos apresuntados controle, elaborados com extrato de frutanos e com farinha de yacon.

\begin{tabular}{|c|c|c|c|}
\hline Parâmetros & $\begin{array}{c}\text { Formulação } \\
\text { controle }\end{array}$ & $\begin{array}{c}\text { Formulação } \\
\text { com farinha } \\
\text { de yacon }\end{array}$ & $\begin{array}{l}\text { Formulação } \\
\text { com extrato } \\
\text { de frutanos }\end{array}$ \\
\hline $\begin{array}{l}\text { Umidade } \\
\left(\mathrm{g} 100 \mathrm{~g}^{-1}\right)\end{array}$ & $78,22^{A}$ & $76,02^{\text {в }}$ & $75,56^{c}$ \\
\hline $\begin{array}{l}\text { Lipídios } \\
\left(\mathrm{g}^{100} \mathrm{~g}^{-1}\right)\end{array}$ & $1,62^{A}$ & $1,83^{A}$ & $1,78^{A}$ \\
\hline $\begin{array}{l}\text { Proteínas } \\
\left(\mathrm{g}^{100} \mathrm{~g}^{-1}\right)\end{array}$ & $13,23^{A}$ & $14,03^{A}$ & $13,61^{A}$ \\
\hline $\begin{array}{l}\text { Cinzas } \\
\left(g_{100} g^{-1}\right)\end{array}$ & $0,060^{A}$ & $0,072^{A}$ & $0,061^{A}$ \\
\hline $\begin{array}{l}\text { Fibras } \\
\left(g^{100} g^{-1}\right)\end{array}$ & $1,44^{\text {в }}$ & $1,45^{\text {B }}$ & $2,78^{A}$ \\
\hline $\begin{array}{l}\text { Carboidratos } \\
\left(\mathrm{g} 100 \mathrm{~g}^{-1}\right)\end{array}$ & $5,43^{\mathrm{B}}$ & $6,60^{A}$ & $6,22^{A}$ \\
\hline 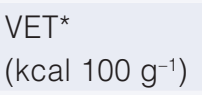 & 89,22 A $^{2}$ & 98,99 A & 95,34 A \\
\hline$K\left(\mathrm{mg} \mathrm{g}^{-1}\right)$ & $0,794^{\text {в }}$ & $0,838^{A}$ & $0,838^{A}$ \\
\hline $\mathrm{Na}\left(\mathrm{mg} \mathrm{g}^{-1}\right)$ & $42,34^{B}$ & $41,46^{c}$ & $43,47^{A}$ \\
\hline
\end{tabular}

Médias seguidas da mesma letra nas linhas não diferem entre si pelo teste de Tukey a $5 \%$ de probabilidade; * Valor energético total. 
apresentou maior teor de sódio em relação ao controle, o que provavelmente se deve à menor umidade, ou seja, maior concentração de sódio no apresuntado, ou à utilização de $\mathrm{NaOH}$ para ajuste do pH durante a obtenção do extrato. A formulação com farinha de yacon apresentou teor de sódio significativamente inferior ao controle. A fécula de mandioca comercial, utilizada no controle, pode possuir maior teor de sódio que a farinha do yacon, o que provavelmente elevou o teor de sódio no apresuntado controle. A maior quantidade de potássio observada nos apresuntados elaborados com yacon, associada aos menores teores de sódio consistem um benefício à saúde, uma vez que o potássio é um facilitador da excreção renal do sódio, auxiliando no processo de regulação da pressão arterial (SANTOS e LIMA, 2009), além de contribuir para a diminuição da excreção urinária do cálcio, sendo adjuvante na prevenção de osteoporose (ADI LEIBA et al., 2005).

As formulações de apresuntado apresentaram diferença significativa ( $p<0,05)$ nos valores das coordenadas cor, luminosidade $\left(L^{*}\right)$, índice de vermelho $\left(a^{\star}\right)$, índice de amarelo $\left(b^{\star}\right)$, saturação $\left(c^{\star}\right)$ e tonalidade $\left(h^{*}\right)$ (Tabela 3).

Pode-se verificar que a luminosidade $\left(L^{*}\right)$ e o índice de vermelho $\left(a^{*}\right)$ diferiram nas três formulações de apresuntado. Na formulação controle, a $L^{*}$ e o $a^{*}$ foram 52,78 e 12,04, respectivamente, superiores aos dos demais apresuntados analisados. Isso significa que o apresuntado controle foi a amostra mais clara e mais vermelha, enquanto que o apresuntado elaborado com farinha de yacon foi o mais escuro $(51,60)$ e o menos vermelho $(11,66)$ (Tabela 3$)$, fatores que podem influenciar em sua aceitação.

Ao avaliarem 13 marcas de presunto cozido comercializadas na República Checa, Válková et al. (2007) observaram que os consumidores dessa região preferiram produtos com maior valor de luminosidade e menor participação da tonalidade vermelha. Isso reforça as observações de García-Esteban et al. (2003) de que a luminosidade pode ser considerada o parâmetro de cor que governa a qualidade da carne e de produtos cárneos, sendo, portanto, o atributo de cor que mais influenciou a aceitação do produto.

Analisando-se os valores de $b^{*}$ dos apresuntados verifica-se que o elaborado com farinha de yacon apresentou maior valor desse parâmetro $(5,74)$. O parâmetro $b^{*}$ expressa a intensidade da cor amarela da amostra, que, para carnes e produtos derivados, se relaciona com a coloração marrom (BARRETO, 2007). Dessa forma, apresuntado elaborado com farinha de yacon apresentou maior intensidade da cor marrom, o que possivelmente se deve à oxidação dos compostos fenólicos do yacon a melanoidinas (CABELLO, 2005) durante o processo de sua secagem. Essas alterações são evidenciadas pelo aumento do ângulo de tonalidade $\left(h^{*}\right)$ do produto e com o tempo de estocagem (JUNCHER et al., 2003; SHERIDAN et al., 2007).

A influência dos índices de vermelho e amarelo torna-se mais facilmente perceptível quando eles são avaliados por meio do índice de saturação $\left(C^{*}\right)$ e do ângulo de tonalidade $\left(h^{*}\right)$ (CONTADO, 2009). Assim, o apresuntado elaborado com farinha de yacon apresentou menor valor de saturação $(12,71)$ e maior valor de tonalidade $(26,19)$ que os demais apresuntados, indicando que esse produto apresentou tonalidade tendendo para amarelo e menor saturação (mais próximo do centro do sólido de cor), o que condiz com a coloração mais escura evidenciada pela luminosidade.

$\mathrm{Na}$ Tabela 4 estão apresentados os valores dos atributos textura dos apresuntados. Não houve diferença significativa $(p<0,05)$ na fraturabilidade das formulações de apresuntado. Observou-se que o apresuntado elaborado com farinha de yacon mostrou maior dureza $(1,22$ kgf) quando comparado aos demais, enquanto o elaborado com extrato de frutanos apresentou menor valor nesse parâmetro (0,82 kgf). Estudos realizados

Tabela 3. Valores médios das coordenadas $L^{*}, a^{*}, b^{*}, C^{*} e h^{\star}$ dos apresuntados controle, elaborados com extrato de frutanos e com farinha de yacon.

\begin{tabular}{cccc} 
Índices & $\begin{array}{c}\text { Formulação } \\
\text { controle }\end{array}$ & $\begin{array}{c}\text { Formulação } \\
\text { com farinha } \\
\text { de yacon }\end{array}$ & $\begin{array}{c}\text { Formulação com } \\
\text { extrato de frutanos }\end{array}$ \\
\hline $\mathrm{L}^{*}$ & $52,78^{\mathrm{A}}$ & $51,60^{\mathrm{C}}$ & $51,96^{\mathrm{B}}$ \\
$\mathrm{a}^{*}$ & $12,04^{\mathrm{A}}$ & $11,66^{\mathrm{C}}$ & $11,78^{\mathrm{B}}$ \\
$\mathrm{b}^{*}$ & $4,69^{\mathrm{C}}$ & $5,74^{\mathrm{A}}$ & $4,77^{\mathrm{B}}$ \\
$\mathrm{C}^{*}$ & $12,93^{\mathrm{B}}$ & $12,71^{\mathrm{C}}$ & $12,99^{\mathrm{A}}$ \\
$\mathrm{h}^{*}$ & $21,42^{\mathrm{C}}$ & $26,19^{\mathrm{A}}$ & $22,02^{\mathrm{B}}$ \\
\hline
\end{tabular}

Médias seguidas de mesma letra nas linhas não diferem entre si pelo teste de Tukey a $5 \%$ de probabilidade.

Tabela 4. Atributos de textura nos apresuntados controle e elaborados com extrato de frutanos e com farinha de yacon.

\begin{tabular}{lccc}
\multicolumn{1}{c}{ Atributos } & $\begin{array}{c}\text { Formulação } \\
\text { controle }\end{array}$ & $\begin{array}{c}\text { Formulação } \\
\text { com farinha } \\
\text { de yacon }\end{array}$ & $\begin{array}{c}\text { Formulação } \\
\text { com extrato } \\
\text { de frutanos }\end{array}$ \\
\hline $\begin{array}{l}\text { Dureza (kgf) } \\
\text { Fraturabilidade } \\
\text { (kgf) }\end{array}$ & $1,099443^{\mathrm{B}}$ & $1,223950^{\mathrm{A}}$ & $0,825614^{\mathrm{C}}$ \\
$\begin{array}{l}\text { Coesividade } \\
\text { Adesividade }\end{array}$ & $0,022214^{\mathrm{A}}$ & $0,021486^{\mathrm{A}}$ & $0,021857^{\mathrm{A}}$ \\
$\begin{array}{l}\text { (kgf.mm) } \\
\text { Flexibilidade }\end{array}$ & $0,002200^{\mathrm{B}}$ & $0,003943^{\mathrm{A}}$ & $0,003757^{\mathrm{A}}$ \\
(mm) & $4,65^{\mathrm{AB}}$ & $4,688^{\mathrm{A}}$ & $4,54^{\mathrm{B}}$ \\
$\begin{array}{l}\text { Mastigabilidade } \\
\text { (kgf.mm) }\end{array}$ & $4,671^{\mathrm{A}}$ & $3,950^{\mathrm{B}}$ & $1,800^{\mathrm{C}}$ \\
\hline
\end{tabular}

Médias seguidas de mesma letra, nas linhas, não diferem entre si pelo teste de Tukey a $5 \%$ de probabilidade. 
por García et al. (2002) relataram que a incorporação de $3 \%$ de fibras de trigo em salame prejudicou a textura do produto, deixando-o com uma dureza maior. Dessa forma, a maior dureza observada na formulação de apresuntado com farinha de yacon provavelmente se deve ao teor de fibra dessa farinha. De acordo com Huidobro et al. (2005) e Mendonza et al. (2001), a dureza representa a força máxima requerida para comprimir a amostra e é o atributo de textura que possui maior importância para o consumidor. Assim, por possuir menor dureza, o apresuntado elaborado com extrato de frutanos tende a apresentar boa aceitação.

A adição da farinha de yacon e do extrato de frutanos conferiu maior adesividade aos apresuntados $(0,0039$ e 0,0037 kgf.mm, respectivamente) em relação ao controle, o que pode ter sido ocasionado pela perda de exsudado, corroborada pela maior perda de água observada nesses apresuntados. Além de água, o exsudado é composto por proteínas e ingredientes da formulação responsáveis por conferirem liga às peças cárneas (LAGE, 2012). Dessa forma, a adição da farinha e do extrato de yacon pode ter prejudicado a retenção de água desses produtos, ocasionando uma maior presença de exsudado na superfície e contribuindo, assim, para a maior adesividade observada.

Embora adesividade, coesividade e mastigabilidade dos produtos adicionados de farinha de yacon e extrato de frutanos tenham sido afetadas negativamente, conforme análise instrumental, essa alteração não foi suficiente para ocasionar uma mudança na textura dos produtos quando avaliados sensorialmente (Tabela 5).

Os atributos sensoriais (sabor, textura, impressão global) dos apresuntados controle e elaborados com extrato de frutanos e com farinha de yacon estão representados na Tabela 5. As comparações desses produtos permitem constatar que a formulação elaborada com extrato de frutanos não se diferenciou significativamente $(p \leq 0,05)$ do apresuntado controle em todos os atributos analisados. Por outro lado, a formulação de apresuntado elaborada com farinha de yacon diferiu das demais, apresentando menores pontuações para

Tabela 5. Atributos sensoriais (sabor, textura, impressão global) dos apresuntados controle e elaborados com extrato de frutanos e com farinha de yacon.

\begin{tabular}{lccc} 
Atributos & $\begin{array}{c}\text { Formulação } \\
\text { controle }\end{array}$ & $\begin{array}{c}\text { Formulação } \\
\text { com farinha } \\
\text { de yacon }\end{array}$ & $\begin{array}{c}\text { Formulação } \\
\text { com extrato } \\
\text { de frutanos }\end{array}$ \\
\hline $\begin{array}{l}\text { Sabor } \\
\text { Textura }\end{array}$ & $7,28^{\mathrm{A}}$ & $6,72^{\mathrm{B}}$ & $7,13^{\mathrm{A}}$ \\
Impressão & $6,95^{\mathrm{A}}$ & $6,70^{\mathrm{A}}$ & $6,68^{\mathrm{A}}$ \\
global & $7,70^{\mathrm{A}}$ & $6,65^{\mathrm{B}}$ & $7,60^{\mathrm{A}}$ \\
\hline
\end{tabular}

Médias seguidas de mesma letra, nas linhas, não diferem entre si pelo teste de Tukey a $5 \%$ de probabilidade. sabor e impressão global $(6,72$ e 6,65), respectivamente. A farinha de yacon apresenta compostos fenólicos que, possivelmente, tenham contribuído para o sabor adstringente do apresuntado e influenciado negativamente o atributo sabor. Adicionalmente, a oxidação desses compostos pode também ter contribuído para a coloração mais escura do apresuntado contendo farinha de yacon, resultando em menores médias para os quesitos sabor e impressão global.

Pode-se afirmar que, sensorialmente, as formulações de apresuntados desenvolvidas neste experimento foram consideradas de boa aceitação sensorial pela escala de avaliação, obtendo valores entre 6 (gostei ligeiramente) e 7 (gostei moderadamente).

Mediante avaliação dos resultados obtidos na presente pesquisa, infere-se que a substituição da água por extrato de frutanos nas formulações de apresuntados torna-se vantajosa, obtendo-se, assim, um produto de melhor qualidade nutricional, que poderá contribuir para melhor saúde do consumidor

\section{Conclusões}

A adição da farinha de yacon ao apresuntado resulta num produto cárneo com melhores teores de sódio, potássio, índice de amarelo e atributos de textura, embora possua sabor e impressão global inferior ao controle.

Extrato de frutanos revela-se adequado para ser utilizado na indústria de alimentos em substituição à água na produção de apresuntados, incorporando a eles substâncias com propriedades funcionais e originando um produto cárneo benéfico à saúde, sem que haja redução na sua aceitação.

\section{Agradecimentos}

Os autores agradecem a CNPq, Capes e Fapemig pelo apoio financeiro.

\section{Referências}

ADI LEIBA, M. D.; VALD, A.; PELEG, E.; SHAMISS, M. D.; GROSSMAN, E. Does dietary recall adequately assess sodium, potassium, and calcium intake in hypertensive patients. Journal of Nutrition, Philadelphia, v. 21, n. 4, p. 462-466, 2005. http:// dx.doi.org./10.1016/j.nut.2004.08.021.

BARRETO, A. C. S. Efeito da adição de fibras como substitutos de gordura em mortadela. 2007. 189 f. Tese (Doutorado em Tecnologia de Alimentos)-Faculdade de Engenharia de Alimentos, Universidade Estadual de Campinas, Campinas, 2007.

BOTEGA, L. M. G.; RAMOS, E. M.; DUTRA, M. P.; TEXEIRA, J. T.; RAMOS, A. L. S.; CONTADO, J. L. Avaliação da cor objetiva de apresuntados elaborados com diferentes concentrações de 
Emprego da farinha e do extrato de frutanos de yacon na elaboração de apresuntados

CONTADO, E. W. N. F. et al.

soro de leite. Higiene Alimentar, São Paulo, v. 23, n. 170-171, p. 499-500, 2009.

BRASIL. Ministério da Agricultura e do Abastecimento. Secretaria da Defesa Agropecuária. Departamento de Inspeção de Produtos de Origem Animal. Instrução Normativa n² 20, de 31 de julho de 2000. Aprova o regulamento técnico de identidade e qualidade de almôndega, de apresuntado, de fiambre, de hambúrguer, de kibe e de presunto cozido. Diário Oficial [da] República Federativa do Brasil, Poder Executivo, Brasília, DF, n. 149, p. 7-12, 3 ago. 2000. Seção 1.

CABELLO, C. Extração e pré-tratamento de frutanos de Yacon, Polymnia sonchifolia. Ciência e Tecnologia de Alimentos, Campinas, v. 25, n. 2, p. 202-207, 2005. http://dx.doi. org/10.1590/S0101-20612005000200003.

CHOI, Y. S.; CHOI, J. H.; HAN, D. J.; KIM, H. Y.; LEE, M. A.; KIM, H. W.; JEONG, J. Y.; KIM, C. J. Characteristics of low-fat meat emulsion systems with pork fat replaced by vegetable oils and rice bran fiber. Meat Science, Barking, v. 82, n. 2, p. 266-271, 2009. http://dx.doi.org/10.1016/j.meatsci.2009.01.019. PMid:20416740

COLMENERO, F. J.; AYO, M. J.; CARBALLO, J. Physicochemical properties of low sodium frankfurter with added walnut: effect of transglutaminase combined with caseinate, $\mathrm{KCl}$ and dietary fibre as salt replacers. Meat Science, Barking, v. 69, n. 4, p. 781-788, 2005. http://dx.doi.org/10.1016/j.meatsci.2004.11.011. PMid:22063157

CONTADO, E. W. N. F. Obtenção, caracterização e utilização dos frutanos de tubérculos do yacon (Smallanthus sonchifolia). 2009. 144 f. Tese (Doutorado em Agroquímica)Universidade Federal de Lavras, Lavras, 2009.

COSTA, M. R.; BERGAMIN FILHO, W.; CIPOLLI, K. M. V. A. B.; SILVEIRA, E. T. F.; FELÍCIO, P. E. Perfil sensorial e aceitação de presuntos crus produzidos por métodos tradicionais e acelerado. Ciência e Tecnologia de Alimentos, Campinas, v. 27, n. 1, 2007. http://dx.doi.org/10.1590/S0101-20612007000100030.

CYRINO, N. A.; BARRETTO, A. C. S. O que a Vitacel pode fazer aos seus embutidos. Revista Nacional da Carne, São Paulo, v. 352, n. 349, p. 110-111, 2006.

DOUGLAS, J. A.; FOLLETT, J. M.; DOUGLAS, M. H.; DEO, B.; SCHEFFER, J. J. C.; LITTLER, R. A.; MANLEY-HARRIS, M. Effect of environment and time of planting on the production and quality of yacon (Smanllanthus sonchifolius) storage roots. New Zealand Journal of Crop and Horticultural Science, Wellington, v. 35, n. 1, p. 107-116, 2007. Disponível em: <http:// hdl.handle.net/10289/5939>.

FERREIRA, D. F. Programa SISvAR: Sistema de Análise de Variância. Versão 3.04. Lavras: UFLA, 2000. Software.

FORTES, R. C. Alimentos prebióticos: efeitos bifidogênicos dos fruto-oligossacarídeos e da inulina no organismo humano.
Revista da Sociedade Brasileira de Farmácia Hospitalar, São Paulo, v. 2, n. 9, p. 16-23, 2006.

GARCÍA, M. L.; DOMINGUEZ, R.; GALVEZ, M. D.; CASAS, C.; SELGAS, M. D. Utilization of cereal and fruit fibres in low fat dry fermented sausages. Meat Science, Barking, v. 60, n. 3, p. 227-236, 2002. http://dx.doi.org/10.1016/S03091740(01)00125-5. PMid:22063393

GARCÍA-ESTEBAN, M.; ANSORENA, D.; GimenO, O.; ASTIASARÁN, I. Optimization of instrumental colour analysis in dry-cured ham. Meat Science, Barking, v. 63, n. 3, p. 287-292, 2003. http://dx.doi.org/10.1016/S0309-1740(02)00084-0. PMid:22062379

GUILLON, F.; CHAMP, M. Structural and physical properties of dietary fibres and consequences of processing on human physiology. Food Research International, Barking, v. 33, n. 3-4, p. 233-245, 2000. http://dx.doi.org/10.1016/S09639969(00)00038-7.

HUIDOBRO, F. R.; MIGUEL, E.; BLÁZQUEZ, B.; ONEGA, E. A comparison between two methods (Warner-Bratzler and texture profile analysis) for testing either raw meat or cooked meat. Meat Science, Barking, v. 69, n. 3, p. 527-536, 2005. http://dx.doi. org/10.1016/j.meatsci.2004.09.008. PMid:22062992

JUNCHER, D.; RØNN, B.; BECK HANSEN, T.; HENCKEL, P.; KARLSSON, A.; SKIBSTED, L. H.; BERTELSEN, G. Effect of pre-slaughter physiological conditions on the oxidative stability of colour and lipid during chill storage of sliced, retail packed roast ham. Meat Science, Barking, v. 63, n. 2, p. 151-159, 2003. http://dx.doi.org/10.1016/S0309-1740(02)00054-2. PMid:22062174

LAGE, F. C. S. Caracterização de apresuntado com baixo teor de gordura formulado com soro de leite e lactulose. 2012. 180 f. Dissertação (Mestrado em Ciência dos Alimentos)Universidade Federal de Lavras, Lavras, 2012.

LATIMER JUNIOR, G. W. Official methods of analysis. 19. ed. Gaithersburg: AOAC, 2012. 3000 p.

MALAVOLTA, E.; VITTI, G. C.; OLIVEIRA, S. A. Avaliação do estado nutricional das plantas: princípios e aplicações. Piracicaba: Potafos, 1997. 319 p.

MARTINS, M. L. R.; DELMACHIO, K. L.; CORDEIRO, A. A. Efeitos da utilização de Smallanthus sonchifolius (yacon) no tratamento de indivíduos com Diabetes Mellitus. Ceres: Nutrição \& Saúde, Rio de Janeiro, v. 6, n. 1, p. 35-43, 2011.

MENDOZA, E.; GARCÍA, M. L.; CASAS, C.; SELGAS, M. D. Inulin as fat substitute in low fat, dry fermented sausages. Meat Science, Barking, v. 57, n. 4, p. 387-393, 2001. http://dx.doi. org/10.1016/S0309-1740(00)00116-9. PMid:22061711

MOURA, C. P. Aplicação de redes neuronais para a predição e otimização do processo de secagem de yacon (Polymnia sonchifolia) com pré-tratamento osmótico. 2004. 
Emprego da farinha e do extrato de frutanos de yacon na elaboração de apresuntados

CONTADO, E. W. N. F. et al.

107 f. Dissertação (Mestrado em Tecnologia de Alimentos)Universidade Federal do Paraná, Curitiba, 2004.

OLIVEIRA, D. F.; COELHO, A. R.; BURGARDT, V. C. F.; HASHIMOTO, E. H.; LUNKES, A. M.; MARCHI, J. F.; TONIAL, I. B. Alternativas para um produto cárneo mais saudável: uma revisão. Brazilian Journal of Food Technology, Campinas, v. 16, n. 3, p. 163-174, 2013. http://dx.doi.org/10.1590/S198167232013005000021.

OLIVEIRA, F. V.; ITAYA, N. M.; FLOH, E. I. S.; CARVALHO, M. A. M. Frutanos em calos Smallanthus sonchifolius (Poepp.) H. Rob. Hoehnea, São Paulo, v. 36, n. 1, p. 89-97, 2009. http:// dx.doi.org/10.1590/S2236-89062009000100004.

PASCOAL, G. B.; FILISETTI, T. M. C. C.; ALVARES, E. P.; LAJOLO, F. M.; MENEZES, E. W. Impact of onion (Allium cepa $L$ ) fructans fermentation on the cecum of rats and the use of in vitro biomarkers to assess in vivo effects. Bioactive Carbohydrates and Dietary Fibre, Amsterdam, v. 1, n. 1, p. 89-97, 2013. http:// dx.doi.org/10.1016/j.bcdf.2013.02.002.

PSZCZOLA, D. E. Starches and gums move beyond fat replacement. Food Technology, Chicago, v. 53, n. 8, p. 74-80, 1999.

RAMOS, E. M.; GOMIDE, L. A. M. Avaliação da qualidade em carnes: fundamentos e metodologias. Viçosa: UFV, 2007. $599 \mathrm{p}$.
ROBERFROID, M. B.; DELZENNE, N. M. Dietary fructans. Annual Review of Nutrition, Palo Alto, v. 18, n. 1, p. 117-143, 1998. http://dx.doi.org/10.1146/annurev.nutr.18.1.117. PMid:9706221

SAAD, S. M. I. Probióticos e prebióticos: o estado da arte. Revista Brasileira de Ciências Farmacêuticas, São Paulo, v. 42, n. 1, p. 1-16, 2006. http://dx.doi.org/10.1590/S151693322006000100002 .

SANTOS, A. C.; LIMA, C. A. Hipertensão de difícil controle: impacto do estilo de vida. Revista Brasileira de Hipertensão, Rio de Janeiro, v. 16, n. 1, p. S5-S6, 2009.

SHERIDAN, C.; O'FARRELL, M.; LEWIS, E.; FLANAGAN, C.; KERRY, J.; JACKMAN, N. A comparison of CIE $\mathbf{L}^{*} \mathbf{a}^{*} \mathbf{b}^{*}$ and spectral methods for the analysis of fading in sliced cured ham. Journal of Optics. A, Pure and Applied Optics, Bristol, v. 9, n. 6, p. S32-S39, 2007. http://dx.doi.org/10.1088/1464-4258/9/6/ so6.

VÁLKOVÁ, V.; SALÁKOVÁ, A.; BUCHTOVÁ, H.; TREMLOVÁ, B. Chemical, instrumental and sensory characteristics of cooked pork ham. Meat Science, Barking, v. 77, n. 4, p. 608-615, 2007. http://dx.doi.org/10.1016/j.meatsci.2007.05.013. PMid:22061949

VIDAL, A. M. A.; DIAS, D. O.; MARTINS, E. S. M. M.; OLIVEIRA, R. S.; NASCIMENTO, R. M. S.; CORREIA, M. G. S. A ingestão de alimentos funcionais e sua contribuição para a diminuição de incidências de doenças. Caderno de Graduação: Ciências Biológicas e da Saúde, Aracaju, v. 1, n. 15, p. 43-52, 2012. 